\title{
Paracoccidioidomycosis in the Central Nervous System
}

\section{Paracoccidioidomicose no sistema nervoso central}

\author{
Paulo Moacir Mesquita Filho10 Agatha Hofmann $^{2}$ Fernanda De Carli ${ }^{2}$ Moisés Augusto Araújo ${ }^{1,3}$ \\ Richard Giacomelli ${ }^{1,3}$ Gregori Manfroi ${ }^{2}$ Elizabeth Leal ${ }^{2}$ Bruna Bley Mattar Isbert ${ }^{2}$ Daniela Schwingel ${ }^{4}$ \\ ${ }^{1}$ Neurology and Neurosurgery Service (SNN), Hospital de Clínicas de \\ Passo Fundo, Passo Fundo, Rio Grande do Sul, RS, Brasil \\ ${ }^{2}$ Academic League, Neurology and Neurosurgery Service, Escola de \\ Medicina, Universidade de Passo Fundo, Passo Fundo, Rio Grande do \\ Sul, RS, Brasil \\ 3 Neurosurgery Department, Hospital de Clínicas de Passo Fundo, \\ Passo Fundo, Rio Grande do Sul, RS, Brasil \\ ${ }^{4}$ Instituto de Patologia de Passo Fundo, Passo Fundo, Rio Grande do \\ Sul, RS, Brasil

\begin{abstract}
Address for correspondence Paulo Moacir Mesquita Filho, MD, Serviço de Neurologia e Neurocirurgia, Hospital de Clínicas de Passo Fundo, Rua Tiradentes, 295, Passo Fundo, Rio Grande do Sul, RS, 99010-260, Brasil (e-mail: pmesquitafilho@hotmail.Com).
\end{abstract} \\ Arq Bras Neurocir 2020;39(4):306-310.
}

\begin{abstract}
Keywords

- neuroparacoccidioidomycosis

- paracoccidioidomycosis

- fungal abscess

\section{Resumo}
Palavras-chave
- neuroparaco- ccidioidomicose
- paracoccidi- oidomicose
- abscesso fúngico

Paracoccidioidomycosis is a systemic mycosis caused by the Paracoccidioides brasiliensis fungus, which is endemic in Latin America. Brazil is the country with the highest number of cases. The affection of the central nervous system (CNS), a potentially fatal condition, occurs in $\sim 12 \%$ of the cases. The following forms of presentation are identified: meningeal, which is unusual; meningoencephalitic; and pseudotumoral, the latter two being more frequent. Imaging tests are essential for the diagnosis, but the histological identification of the fungus is required for confirmation of the pathology. The clinical picture depends on the neuraxial location. We present a case of a male rural worker, with expansive lesions in the CNS compatible with paracoccidioidomycosis.

A paracoccidioidomicose é uma micose sistêmica, endêmica na América Latina, causada pelo fungo Paracoccidioides brasiliensis. O Brasil é o país com o maior número de casos. A afecção do sistema nervoso central (SNC), condição potencialmente fatal, ocorre em torno de $12 \%$ dos casos. Identificam-se as seguintes formas de apresentação: meníngea, mais rara; meningoencefálica; e pseudotumoral, sendo estas duas últimas mais frequentes. Os exames de imagem são fundamentais no auxílio diagnóstico, mas a identificação histológica do fungo é necessária para confirmação. O quadro clínico depende da localização no neuroeixo. Apresentamos o caso de um homem, trabalhador rural, com formações expansivas no SNC compatíveis com paracoccidioidomicose.
\end{abstract}

\section{Introduction}

Paracoccidioidomycosis (PCM) is a systemic infection caused by the dimorphic fungus Paracoccidioides brasiliensis, with an annual incidence of 1 to 3 cases per 100,000 inhabitants in endemic areas. Brazil accounts for at least $80 \%$ of the cases. ${ }^{1}$
The primary infection is usually asymptomatic, the disease usually occurs months or years after the primary infection, and most of the times the lungs are affected; but its hematogenous or lymphatic dissemination enables the disease to reach any other organ. ${ }^{2}$ The central nervous system (CNS) is affected in around $12 \%$ of the cases, and, in received

July 27, 2017

accepted

October 4, 2017
DOI https://doi.org/

10.1055/s-0036-1594303. ISSN 0103-5355.
Copyright (e 2020 by Thieme Revinter

Publicações Ltda, Rio de Janeiro, Brazil
License terms

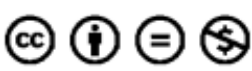



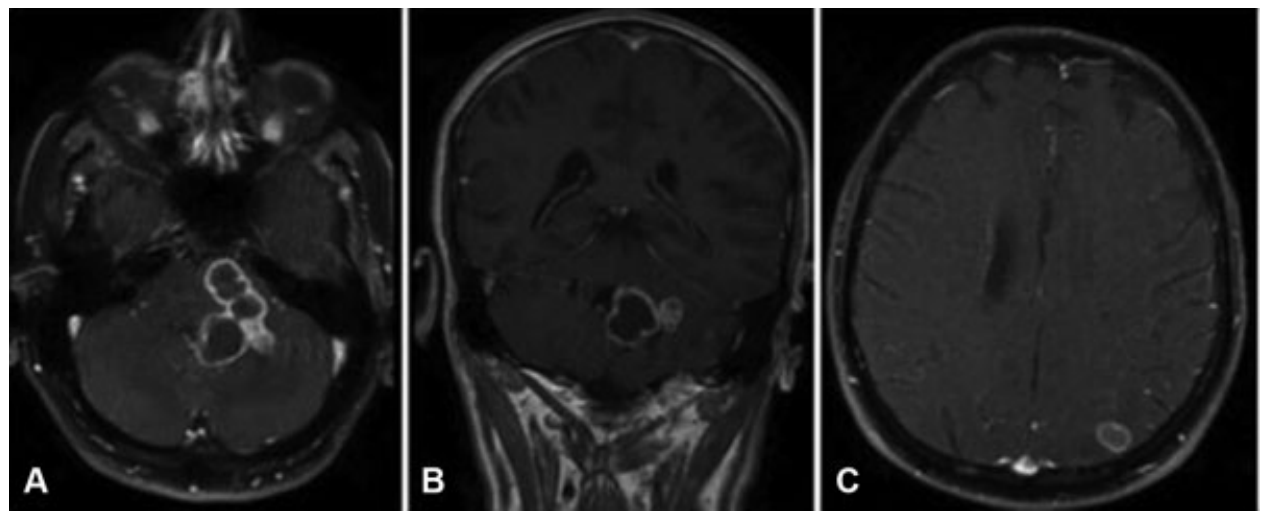

Fig. 1 (A) Magnetic resonance imaging (MRI), T1-weighted axial sequence with gadolinium, showing an irregular lesion affecting the middle cerebellar peduncle and cerebellar parenchyma, with strong contrast enhancement; (B) MRI, T1-weighted sequence with gadolinium, coronary sections, showing the relationship of the lesion with the fourth ventricle, with displacement of the ventricle, but without invasion; (C) MRI, T1weighted sequence with gadolinium, axial, supratentorial, showing an annular lesion in the left parietal region, with strong contrast enhancement.

these, supratentorial lesions are more common. ${ }^{3}$ Because neuroparacoccidioidomycosis (NPCM) causes permanent sequelae, it should be considered in the differential diagnosis of the meningoencephalic and expansive CNS processes. ${ }^{4}$

\section{Case Report}

A white male patient, 53 years old, rural worker with a history of alcoholism and smoking, presented a sudden picture of dysarthria and difficulty to walk. The patient reported, however, progressive symptoms for months, with vertigo, episodes of fever, especially in the afternoon, and significant weight loss. Upon physical examination, he presented cerebellar syndrome, nystagmus and positive Romberg sign, as well as septic teeth. In primary care, a cranial computed tomography (CT) was performed, with a hypodense image in the bridge region and the left middle cerebellar peduncle, in addition to the hypodense lesion in the left parietal region. The initial laboratory exams evidenced an increase in the inflammatory tests. Magnetic resonance imaging(MRI) of the encephalon was then performed, and it revealed expansive lesions affecting the left middle cerebellar bridge and peduncle, gadolinium annular enhancement, and perilesional edema (-Fig. 1A, B, C). There were also lesions in the cerebellar parenchyma and in the left parietal region. The lesions presented hypersignal in their central region in $\mathrm{T} 2$, and restriction to diffusion. An oncologic investigation was performed, but no primary neoplastic lesion was found. The chest CT showed an unspecific pattern, with no lesion compatible with neoplasia. The patient was then submitted to a neurosurgical procedure for diagnostic elucidation and excision of the lesion with mass effect in the posterior fossa. During the procedure, an encapsulated lesion was evidenced, and, when incised, it drained content compatible with a purulent secretion. The lesion was drained, and the partial removal of the capsule was performed, which was extremely adhered to the cranial nerves and to the brainstem. After the procedure, the patient evolved with regression of the preoperative neurological deficits. The analysis of the collected secretion evidenced a large amount of polymorphonuclear leukocytes and blastoconidia in budding. The anatomopathological examination confirmed PCM ( - Fig. 2A, B, C). After one week of antibiotic therapy, a neuroimaging (CT) scan of the skull was performed, evidencing a reduction in the mass effect and presence of portion enhancement of the capsule that had

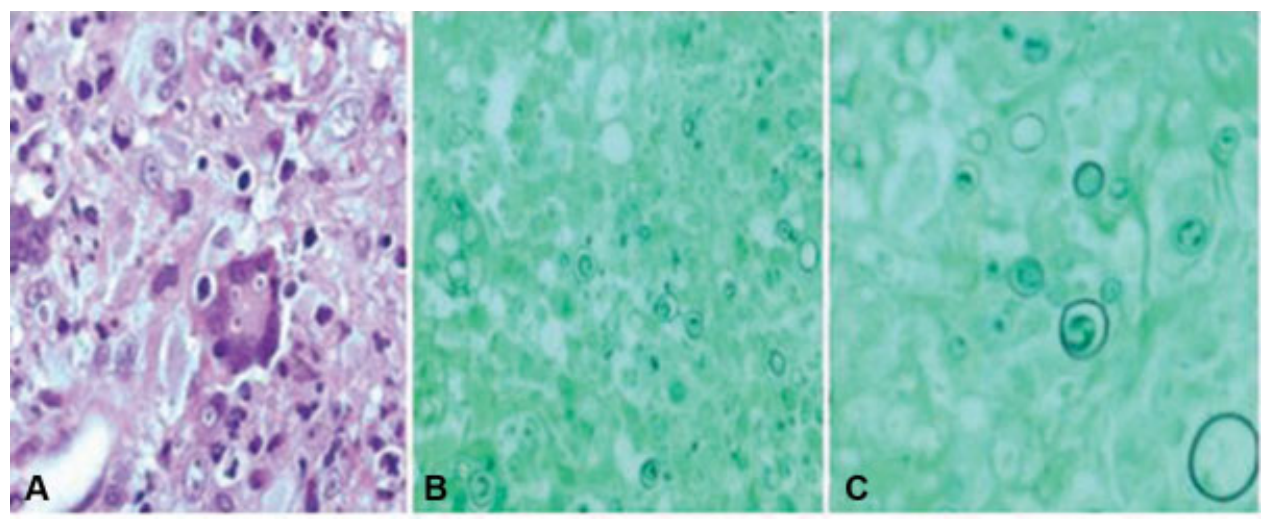

Fig. 2 (A) Hematoxylin and eosin (HE) staining (histological sections), increase of 100x, evidencing a multi-inflammatory process with multinucleated giant-cell and fungal structures inside it. (B) Grocott staining, increase of 100x and 400x, showing fungal structures - with typical Paracoco morphology (“Mickey head”) - evidenced by the staining. 

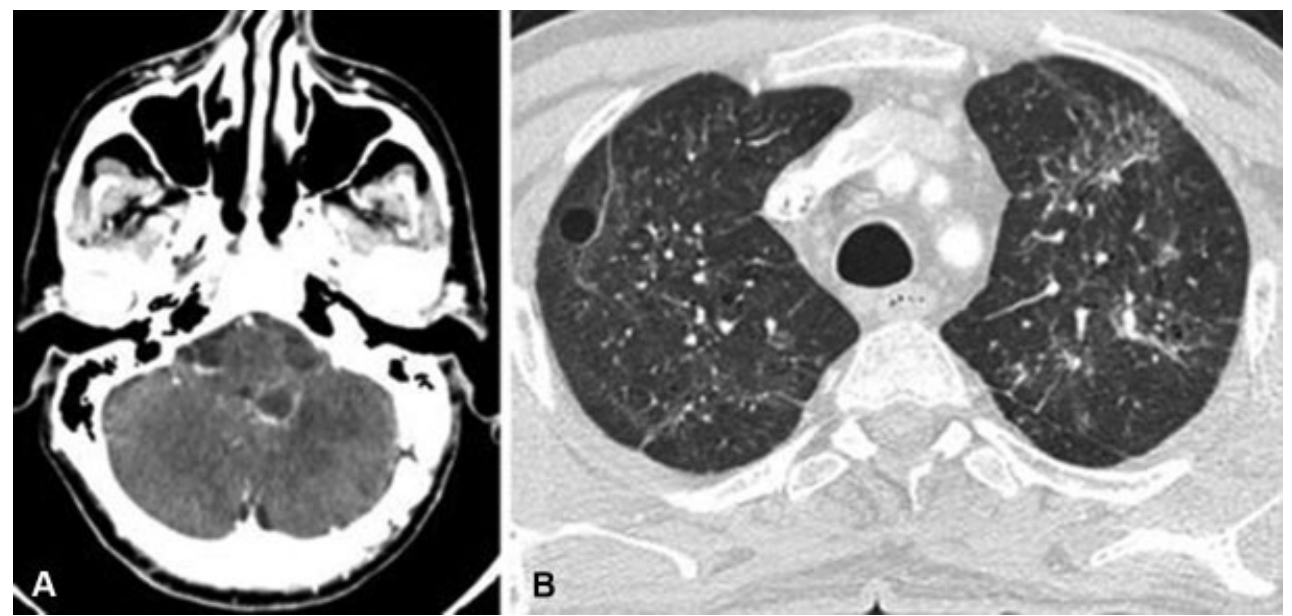

Fig. 3 (A) Post-operative cranioencephalic computed tomography (CT) scan with contrast, evidencing the area of surgical manipulation, as well as persistence of the enhancement in part of the capsule that was not surgically approached; (B) chest CT scan showing reticular parenchymal opacities and a budding-tree pattern in the upper segments of both lungs.

not been approached (-Fig. 3A). The evolutionary chest CT identified parenchymal opacities of the reticular pattern, associated with opacities with a budding tree pattern, predominantly in the upper segments of the lungs, as well as bronchiectasis and a small localized calcification ( - Fig. $\mathbf{3 b}$ ). The patient was then submitted to antibiotic therapy with amphotericin B for 15 days, and, after hospital discharge, itraconazole for 6 weeks. The patient is being monitored with radiological control, and since hospital discharge, he has presented a gradual reduction in the lesions.

\section{Discussion}

Paracoccidioidomycosis (PCM) is a systemic infectious disease, endemic in subtropical areas of Central and South America. Brazil accumulates $\sim 80 \%$ of the cases described. ${ }^{1}$ It is estimated that, in endemic areas, the incidence of PCM varies from 3 to 4 cases per 100,000 inhabitants per year. ${ }^{5}$ The disease can occur in individuals of any age range, including in 2-year-old children, but it mainly affects those aged between 30 and 50 years. It is more prevalent in males. There is frequent association of PCM with smoking and alcoholism. ${ }^{5}$

The infection occurs by inhalation of conidia, which form a focus on the primary pulmonary complex. Extrapulmonary foci occur by the lympho-hematogenous dissemination of the fungus. The infection occurs mainly in the first 2 decades of life, but the clinical manifestations develop between 30 and 50 years of age, with the reactivation of the latent endogenous focus. ${ }^{4}$

Paracoccidioidomycosis can affect any organ. The lungs are most commonly affected (50-100\%), followed by the skin, mucous membranes, lymph nodes, adrenal glands, CNS, liver and bones. Impairment of the CNS occurs in 12\% of the cases. ${ }^{3}$ It is a serious and potentially incapacitating form of the disease, which is often fatal. Therefore, it should be considered in the differential diagnosis of meningoencephalic and expansive CNS processes in order to establish early treatment and avoid the emergence of incapacitating sequelae. ${ }^{4}$
The neurological infection is described as secondary, and the main form of dissemination is hematological, due to the predominance of lesions in areas with high blood flow. ${ }^{3}$ Immunologic factors may favor CNS impairment. ${ }^{1}$ The involvement of the lungs, which is detectable through radiology, is more frequent in cases of neurological injury than in other forms of PCM: 61 to $83 \%$ of patients with NPCM present pulmonary lesions, compared with $5 \%$ and $3.1 \%$ of patients with osteoarticular involvement and involvement of the tube of the digestive tract respectively. ${ }^{4}$ Other studies have demonstrated a frequency of up to $93 \%$ of concomitant pulmonary and neurological impairments, which makes radiography useful in cases of suspected CNS lesions. ${ }^{6}$

The clinical presentation of NPCM can be meningeal, meningoencephalic and pseudotumoral. ${ }^{7}$ The latter is the pseudotumoral is the most frequent form, and corresponds to $\sim 96 \%$ of the cases, and may mimic other pathologies and presentations, such as: abscesses, granulomas, nodules or intraparenchymal cysts, preferably with supratentorial localization, most commonly affecting the cerebral hemispheres. Infratentorial lesions are also described, involving the bridge, the bulb, and mainly the cerebellum. The signs and symptoms are of expansive lesion in the CNS with intracranial hypertension $(\mathrm{IH})$ : vomiting, headache and papilledema.

Pedroso et $\mathrm{al}^{3}{ }^{3}$ in their systematic review of 257 patients with NPCM, stipulated the most affected CNS sites: the cerebral hemispheres (47.6\%), mainly the frontal and parietal lobes, and the cerebellum (28.8\%), which is responsible for walking disorders, dizziness, nausea, vomiting and diplopia, as well as rapid progression to $\mathrm{IH}^{5}$ Spinal cord impairment is described as rare. Intramedullary granulomas, in general, cause spinal cord compression, determining a severe and rapidly progressing condition. ${ }^{8}$ Spinal cord injuries predominate in the thoracic segment, given the greater blood supply of the region and the hematogenous dissemination of P. brasiliensis. ${ }^{3}$ Lesions of the encephalic parenchyma may occur as solitary or multiple granulomas. They present as 
histiocytic and giant-cell infiltrates, with central areas of necrosis. Fungi are abundant in the periphery of the granulomas. ${ }^{4}$ The meningeal presentation is regarded as rare. ${ }^{3}$ It consists of a chronic inflammatory process at the base of the encephalon, which may cause radicular or myeloid symptomatology, similar to tuberculous meningoencephalitis. ${ }^{3}$

In $21 \%$ of the cases, the neurological symptoms begin before the systemic ones; in 33\%, they occur simultaneously; and in $46 \%$, the neurological symptoms arise after systemic symptoms. The symptoms vary depending on the affected site: in cases of intraparenchymal affection, there are headache and locational symptoms (and the most common are pyramidal); in cases of affection of the meninges, meningeal syndrome develops, with headache and neck stiffness; and in cases of cerebellar affection, the symptoms are gait disturbances, dizziness, nausea, vomiting and diplopia. Motor and sensory deficits, cerebellar ataxia, cranial nerve palsy, epileptic seizures, disturbances in consciousness and mood, aphasia, signs of intracranial hypertension and hydrocephalus may also occur. Neuroparacoccidioidomycosis may also be asymptomatic, with an incidental diagnosis. ${ }^{9}$

The lack of specificity of the symptoms, the low sensitivity of the diagnostic tests, the isolated occurrence of NPCM, and the lack of previous systemic infection make the diagnosis of NPCM difficult. ${ }^{4,10}$ In cases of multifocal involvement, classic symptoms of other systems may help in the clinical reasoning. In this context, it is important to perform chest radiography, given the high frequency of association between pulmonary and neurological impairments. ${ }^{3}$

Complementary laboratory exams are generally unspecific, but they may be indicative of NPCM. Neuroimaging studies (CT and MRI) are considered essential to reveal the neurological impairment of the disease, especially in the granulomatous presentation. However, it may appear as other expansive intracranial processes in imaging studies. Thus, the definitive diagnosis is obtained only when the fungi are histologically observed, or isolated from biopsies, or from the cerebrospinal fluid (CSF, which is rare) ${ }^{4}$

The analysis of the CSF has low sensitivity and specificity, and $P$. brasiliensis research is rarely positive, either by culture or direct examination. ${ }^{7}$ Depending on the level of impairment of the meninges, the CSF test may be normal.

Imaging exams are fundamental to guide the diagnosis of NPCM. In CTs, paracoccidioidomycotic granulomas present as rounded, hypodense lesions, with a hypercaptant halo in a ring pattern, of variable location, without signs of bone formation or destruction. The MRI is considered the best non-invasive method to evaluate lesions of the meninges or parenchyma, because it is more sensitive to identify intraparenchymal lesions, especially infratentorial lesions, including those in the cerebellum, cerebral trunk and spinal cord. ${ }^{9}$ Therefore, it should be the gold standard to assess cases of suspicion of NPCM. The MRI may not only show parenchyma involvement and/or involvement of the meninges, but may also be useful to differentiate those lesions from other lesions. ${ }^{11}$ The lesions were characterized by ISO (Isointense) or hyposignal in T1, hyposignal in $\mathrm{T} 2$, with peripheral edema and nodular or ring enhancement after contrast administration. ${ }^{12}$ However, both imaging methods show unspecific characteristics, and histopathology is the only way to confirm the diagnosis. ${ }^{13}$

The differential diagnosis of the granulomatous presentation of NPCM should include toxoplasmosis, neoplasms, particularly malignant gliomas and metastatic tumors, tuberculosis, bacterial abscesses, neurocysticercosis, as well as other mycoses such as cryptococcosis and histoplasmosis. The meningoencephalic presentation should include meningoencephalitis, particularly the tuberculous kind. ${ }^{13}$

Medications are the usual treatment for NPCM. The use of corticosteroids remains controversial. A positive response to dexamethasone indicates an important action of inflammation and, therefore, edema in the mechanism of the pathogenesis of neurological symptoms. However, prolonged use of corticosteroids in infectious diseases for which a specific therapy has not yet been established may cause dissemination and worsening of the lesions. ${ }^{14}$ Thus, in the case herein reported, we opted not to use corticosteroids due to the lack of knowledge of the etiological agent of the preoperative lesion.

Sulfamidotherapy has been one of the treatments of choice for NPCM, or it is used to maintain the treatment, especially the association of sulfamethoxazole and trimethoprim (SMX-TMP), due to its good penetration in the bloodbrain barrier (BBB) and low toxicity. In more severe cases, such as those of children and adolescents, and of adults with disseminated presentation, amphotericin $\mathrm{B}$, a rapid-acting medicine, may be used, but it should be limited because of its high hepatic, renal and cardiac toxicity. Amphotericin B should preferably be used in a hospital setting, because it sometimes requires intrathecal administration, since it has lower penetration in the BBB. Azolic derivatives, such as itraconazole, remain a part of the therapeutic arsenal. Although these drugs do not reach levels comparable to those of the SMX-TMP in the CNS, 6,15 they have presented therapeutic success, as evidenced in an increasing numbers of reports. This is possibly due to the greater adherence to treatment, because of the facilitated posology. ${ }^{13,15}$

In addition to the conservative treatment, surgical resection is indicated, with the patient having clinical conditions and the lesion being surgically accessible, in cases of initial diagnostic hypothesis of neoplasia, progressive spinal cord compression, treatment inefficacy, and brainstem or ventricular system compression. ${ }^{1,3}$ Even with the option of surgical treatment, medication therapy should be initiated early, because the manipulation of granulomas can cause the dissemination of the disease. ${ }^{1}$

No trustworthy parameters have yet been established to indicate the ideal and safe time to discontinue the therapy, as well as for early reintroduction in case of recurrence. The literature advises that the duration of the treatment is related to reaching the criteria for clinical and radiological cure. ${ }^{4}$

Neuroparacoccidioidomycosis is a disease of high incapacitating power, and the occurrence of sequelae is common, especially motor ones. ${ }^{3}$ The mortality is high, estimated at around $53 \%{ }^{9}$ The factors predictive of a worse prognosis are: advanced age, comorbidities, multisystemic impairment, and meningoencephalic presentation associated with hydrocephaly. ${ }^{1}$ 


\section{Conclusion}

Involvement of the CNS in PCM is a severe and incapacitating form of the disease. Its diagnosis is a challenge due to the absence of specificity of the exams and the clinical presentation, which mimics other CNS pathologies. Thus, it is essential to consider NPCM a diagnostic hypothesis in patients with clinical and neurological conditions in endemic regions such as Brazil, especially in rural areas. Due to the prevalence of concomitant lung involvement, it is essential to perform chest radiography. Finally, the diagnostic suspicion enables us to initiate early treatment with antifungal agents, and to analyze the need for surgical intervention, to avoid disabling sequelae.

\section{Conflict of Interests}

The authors have no conflict of interests to declare.

\section{References}

1 Fagundes-Pereyra WJ, Carvalho GTÇ, Góes AM, das Chagas Lima e Silva F, de Sousa AA. [Central nervous system paracoccidioidomycosis: analysis of 13 cases]. Arq Neuropsiquiatr 2006;64(2A):269-276

2 Quintero-Cusguen P, Parra-Izquierdo V, Calderon CM, Martinez G, Sierra Y. Neuroparacoccidioidomicosis pseudotumoral en paciente inmunocompetente. Acta Neurol Colomb 2013;29:203-207

3 Pedroso VSP, Vilela MdeC, Pedroso ERP, Teixeira AL. [Paracoccidioidomycosis compromising the central nervous system: a systematic review of the literature]. Rev Soc Bras Med Trop 2009;42(06):691-697

4 Pedroso VSP. Estudo clínico e experimental da paracoccidioidomicose [Dissertação]. Belo Horizonte: Universidade Federal de Minas Gerais; 2009
5 Shikanai-Yasuda MA, Telles Filho FdeQ Mendes RP, Colombo AL, Moretti ML. [Guidelines in paracoccidioidomycosis]. Rev Soc Bras Med Trop 2006;39(03):297-310

6 Francesconi F, da Silva MT, Costa RLB, et al. Long-term outcome of neuroparacoccidioidomycosis treatment. Rev Soc Bras Med Trop 2011;44(01):22-25

7 da Silva CEAP, Cordeiro AF, Gollner AM, Cupolilo SMN, QuesadoFilgueiras M, Curzio MF. [Paracoccidioidomycosis of the central nervous system: case report]. Arq Neuropsiquiatr 2000;58 (3A):741-747

8 Colli BO, Assirati Júnior JA, Machado HR, et al. Intramedullary spinal cord paracoccidioidomycosis. Report of two cases. Arq Neuropsiquiatr 1996;54(03):466-473

9 Cunha MLV, Onuki CA, Neto JFAA. Piekala ALB - Neuroparacoccidioidomicose mimetizando metástase cerebral: relato de caso e revisão da literatura. J Bras Neurocirurg 2012;23(03):226-233

10 Marques SA. Paracoccidioidomicose: atualização epidemiológica, clínica e terapêutica. An Bras Dermatol 2003;78(02):135-146

11 Leal Filho MB, Borges G, da Silva RG Jr, et al. [Paracoccidioidomycosis in cerebral hemisphere and brainstem: case report]. Arq Neuropsiquiatr 2006;64(3A):686-689

12 Reis F, Collier PP, Souza TF, et al. Neuroparacoccidioidomycosis (NPCM): magnetic resonance imaging (MRI) findings. Mycopathologia 2013;175(1-2):181-186

13 Paniago AMM. Paracoccidioidomicose: estudo clínico e epidemiológico de casos observados em 25 anos, no estado do Mato Grosso do Sul, Brasil [thesis]. Rio de Janeiro: Instituto Oswaldo Cruz; 2005

14 de Moura LP, Raffin CN, del Negro GMB, Ferreira MS. [Paracoccidioidomycosis evidencing spinal cord involvement treated with success by fluconazole]. Arq Neuropsiquiatr 1994;52(01):82-86

15 Villa LA, Tobón A, Restrepo A, et al. Central nervous system paracoccidioidomycosis. Report of a case successfully treated with itraconazol. Rev Inst Med Trop São Paulo 2000;42(04): $231-234$ 